\title{
Developing an Expert System for Water Types Identification in the Context of Physicochemical Indicators in Aridity-based Regions
}

\author{
Shah Murtaza Rashid Al \\ Masud \\ Faculty of Computer Science and \\ Information Systems \\ Najran University \\ Najran, Saudi Arabia
}

\begin{abstract}
Expert System (ES) is an Artificial Intelligent (AI) technique and program that uses knowledge and inference procedures to solve problems that are difficult enough to require significant human expertise for their solutions. The proposed ES presented in this paper is able to easily identify the major water quality types and make appropriate recommendations according to the users' needs. Although water is important for all living substances human-animals-fish-plants-agriculture, but water is continuously contaminated naturally and artificially which ultimately affects on its quality. Due to the lack of knowledge about the quality of water, the harmful effects of water to the animals' body including human, and also necessity of ideal water for agriculture remain unknown. To identify the types of water the researchers had to analyze the physicochemical (physical + chemical) indicators of water such as, positive hydrogen-pH, total dissolved solids-TDS, electrical conductivity-EC, and temperature- $\mathrm{T}^{0} \mathrm{c}$. The motivation behind this work was due to the insufficient knowledge about the quality of water and the need to provide novel approaches towards water quality identification and management. A rule-based, web enabled expert system shell: expertise2go was used to design about 56 rules which involved a knowledge component, decision component, design component, graphical user interface component, and the user component.
\end{abstract}

\section{General Terms}

Artificial Intelligence, Expert System

\section{Keywords}

Expert System, Artificial Intelligence, Water Types, Rulebased, Knowledge

\section{INTRODUCTION}

Expert systems (ES) are a branch of artificial intelligence (AI), and were developed by the AI community in the mid1960s [1]. One can infer from this definition that expertise can be transferred from a human to a computer and then stored in the computer in a suitable form that users can call upon the computer for specific advice as needed. Then the system can make inferences and arrive at a specific conclusion to give advices and explains, if necessary, the logic behind the advice. ES provide powerful and flexible means for obtaining solutions to a variety of problems that often cannot be dealt with by other, more traditional and orthodox methods [2]. The four main components of knowledge-based systems KBS are: a knowledge base, an inference engine, a knowledge engineering tool, and a specific user interface. Some of KBS important applications include the following: medical treatment, engineering failure analysis, decision support, knowledge representation, climate forecasting, decision making and learning, and chemical process controlling [2]. Previous work has shown that a system with water quality type identification was very limited.

A well-designed expert system is able to explicitly explain in detail the reasoning that led to a conclusion. Depending on the software and hardware, expert systems may respond faster than a human expert. A multi-user expert system can serve more users at a time.

By taking the above considerations into the account, our contributions are as follows:

- Analysis the factors of physical and chemical indicators of water that are directly related to its quality.

- Identify the major water quality types, namely: neutrality of water, fresh water types, drinking water quality, salinity, acidity, and alkalinity of water according to the factors as mentioned before for designing the proposed expert system.

- Design a rule-based expert system which is able to analysis rules and facts automatically according to the users' demands and also able to make necessary recommendations when needed following the rules of certainty factors $(\mathrm{CF})$.

After analyzing the physicochemical indicators of water our expert system classified and obtained the result of water quality types into: neutral, acidic, severe acidic, alkaline, brine, saline, slightly saline, moderate saline, highly saline, sea and rain water, fresh water, drinking and excellent drinking water including bottled drinking water, brackish to highly brackish water. Depending on the water quality types the proposed expert system also made necessary recommendations and actions for the human life and life stock; aquatic life and fresh water fish; plants; cattle and baby calves; sea fish-animal-plants.

The proposed expert system will be very helpful for the researchers to indentifying water types, and recommendations necessary for life stock, aquatic life, cattle, and plants. As the proposed system is web-based, so at anytime from any place any user can access to it and get recommendations he needed.

This paper is organized in this way, Section 2 Problem definition. Section 3 Analysis the major types of water quality. Section 4 Expert system's main components and an analytical model for the proposed system. Section 5 Design of the proposed expert system. Section 6 Implementation of the 
system, Section 7 Conclusion and future work, and finally Section 8 References.

\section{PROBLEM DEFINITION}

One of the main functions of water is movement that is called as water life cycle. This water cycle operates through a number of natural processes; these are evaporation, transpiration and precipitation. In evaporation level water evaporated from ocean surfaces combines with water is evaporated from freshwater sources such as rivers, lakes and streams to produce clouds. The clouds, in turn, produce precipitation, 78 percent of which falls back into oceans while the remaining 22 percent falls back on land.

Transpiration, on the other hand, is the loss of water by plants. Transpiration rates depend upon temperature, humidity and wind speed conditions near the leaves of plants. And since plants draw water from the soil, transpiration rates can greatly affect soil moisture content. Soil water loss resulting from both transpiration and evaporation is called evapotranspiration.

When precipitation reaches the ground, it follows two basic pathways: surface flow and infiltration. As water soaks into the subsurface through infiltration, it moves through the pores of the soil until the soil reaches saturation. Once infiltrated, water continues to filter through soil or rock through vertical movement called percolation. Percolation results in the movement of water from the soil layer to groundwater. Underground formations that contain groundwater are called aquifers as shown in Figure 1.

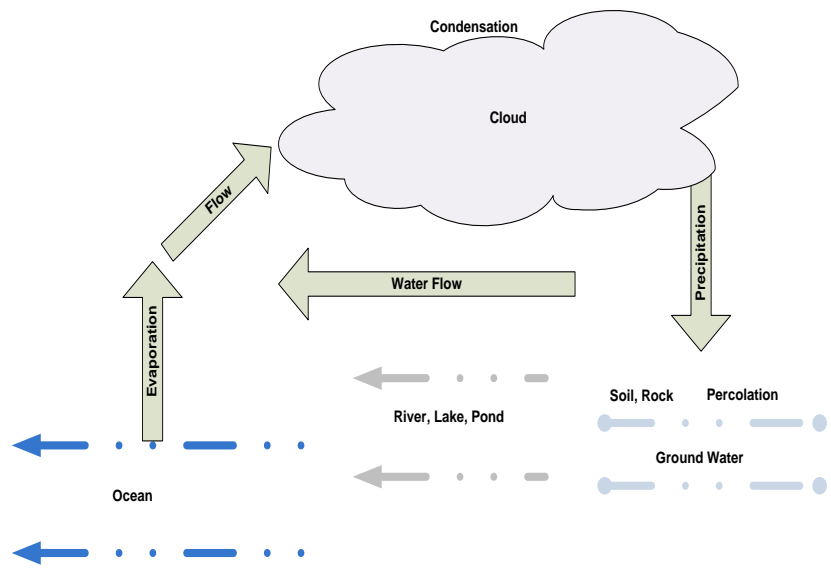

Fig 1: Water Life cycle

As everybody knows nature does not create new water, it constantly recycles the same water and due to the hydrologic cycle the water in nature is also continuously differentiated for its quality. Identifying the types of water quality problems in aridity and semi-aridity-based regions depend on the body of surface of ground water which is every time contaminated by natural influences and human influences. Without human influences water quality would be determined by the weathering of bedrock minerals, by the atmospheric processes of evapotranspiration and the deposition of dust and salt by wind, by the natural leaching of organic matter and nutrients from soil, by hydrological factors that lead to runoff, and by biological processes within the aquatic environment that can alter the physical and chemical composition of water [3]. Typically, water quality is determined by comparing the physical and chemical characteristics of a water sample with water quality guidelines or standards.
Analyzed the above discussion researchers found several types of water those are available either in oceans, or in rivers, lakes, ponds or in ground as mentioned below.

1. Fresh water: Depends on the circumstances the source of fresh water might be bottled drinking water, tap water, etc. The fresh water might be excellent in taste, or excellent drinking water from carbon filtration, or fresh water with a bitter taste (mere acidic) which is not acceptable for human life, but acceptable for fresh water fish, plants, and aquatic life; fresh water might be neutral and ideal for drinking from reverse osmosis; it might be soft water.

2. Acidic water: In water if the temperature level is increased it means the level of hydrogen ion is increased as a result the acidity level will be increased. Depends on the factors of water quality context the acidic water might be severe acidic include a bitter metallic taste and corrosion (oxidization), which is harmful for human life, and agriculture; it's also can possible to find mere acidic water in some water reservoir or sources

3. Saline water: Saline water is mostly found in seawater and river water. Depends on the location and circumstances the saline water is classified into slightly saline water, which may cause mild diarrhea; slightly saline water is unacceptable for life stock. Depends on the factors of water quality context the saline water might be moderately and severe saline water, these types of water should be avoided, these are also harmful for young animals and cattle; mildly basic saline water also should be avoided, which may cause harmful for life stock.

4. Alkaline water: In water if the temperature level is decreased it means the level of hydroxide ion is increased as a result the alkaline level will be increased. Alkaline water may be severely alkaline water which should be avoided under any circumstances, it's soda like taste, and alkaline water might be hard water; mildly and very mildly basic water.

5. Brackish: Brackish is another water type that might be mildly basic brackish, even highly brackish. The salinity level is more than fresh water but less than sea water. This water type is safety for adult ruminants but harmful for cattle and baby calves.

6. Sea water: Almost all the sea water is salty contains high degree of salts, acceptable for sea fish-animals-plants.

7. Rain water: Depends on the chemical circumstances in water rain water may be acid rain, and normal rain water

8. Brine: Water having more sodium chloride called brine. It could be classified into severe to mildly basic brine that is unsafe, should not be used under any circumstances.

Although many scientific measurements are used to define the types of water quality, but it is not easy to say that, "this water is good" or "this water is bad". After all water that is good for human life, may not be good for animals, aquatic life, or plants life.

Some traditional methods and equipments are available for identifying the water quality are secchi disks (measure water clarity), probes, nets, gauges, meters, and laboratory test, which only can give us data of water quality factors, but cannot analysis data, and hence cannot provide the results the 
users needed. But, expert system is very much responsive in this regard and able to give appropriate results.

In this paper researchers proposed ES with facts and rules in a form that it could easily be evaluated water types and made necessary decisions.

\section{ANALYSIS OF THE MAJOR TYPES OF WATER QUALITY}

As everybody already known that water is indispensable for life for every organism and for healthy ecosystems. But its quality varies region to region worldwide. The water quality worldwide depends on several factors such as, soil structure, groundwater, and water table. In most of the cases water quality in aridity-based regions, in the context of its physicochemical indicators, depends on certain parameters including saturation percent of dissolved oxygen, biochemical oxygen demand, fecal coli forms, $\mathrm{pH}$, nitrate, total phosphate, temperature deviation, total dissolved solids (TDS), electrical conductivity (EC) and turbidity. In this paper researchers emphasized over the physical and chemical quality indicators, such as $\mathrm{pH}$, TDS, EC, and Temperature for water types identification [4] [5] [6]. The amount of these quality factors in all types of water is not same. That is why the quality of water is varied and is classified into different classes [7-10].

Water salinity or sodicity (in some cases alkalinity) globally depend on the following factors: Temperature, TDS (Total Dissolved Salts/ Solids: mg/L), EC (Electrical conductivity: $\mu \mathrm{S} / \mathrm{cm}$ ), SAR (Sodium Absorption Ratio), ESP (Exchangeable Sodium Percentage), $\mathrm{pH}$ (Positive Hydrogen), and Anions and Cations: eg. $\mathrm{Ca}^{2+}, \mathrm{Mg}^{2+}, \mathrm{Na}^{+}, \mathrm{Cl}^{-}, \mathrm{SO}_{4}{ }^{2-}, \mathrm{CO}_{3}{ }^{2-}, \mathrm{HCO}_{3}^{-}$[11]. Salt concentrations are expected to be high in arid or semiarid areas where evaporation usually exceeds precipitation. As water evaporates from existing water bodies, salt concentrations increase like in the aridity-based regions. Because precipitation itself contains small traces of salts, evaporation after a rain leaves salts in the soil. These salts may be carried in runoff during the infrequent rains. The most influential water quality guideline on crop (irrigation) productivity is the water salinity hazard as measured by electrical conductivity $\left(\mathrm{EC}_{\mathrm{w}}\right)$ [12]. The primary effect of high $\mathrm{EC}_{\mathrm{w}}$ water on crop productivity is the inability of the plant to compete with ions in the soil solution for water (physiological drought). The higher the EC, the less water is available to plants, even though the soil may appear wet. Because plants can only transpire "pure" water, usable plant water in the soil solution decreases dramatically as EC increases. Electrical conductivity is often used as an estimate of total dissolved salts/ solids (TDS) content of water samples. The TDS unit is measured by $\mathrm{mg} / \mathrm{L}$ (milligram per liter) or ppm (particles/ parts per million), where $1 \mathrm{mg} / \mathrm{L}=1 \mathrm{ppm}$; the $\mathrm{EC}$ unit is measured by $\mu \mathrm{S} / \mathrm{cm}$ (micro-Siemens per centimeter) at temperature level 25 degree Celsius (C). It also shows relationship between TDS and EC in natural water. A relationship of TDS $(\mathrm{mg} / \mathrm{L})=0.64 * \mathrm{EC}(\mu \mathrm{S} / \mathrm{cm})$, or TDS $(\mathrm{mg} /$ $\mathrm{L})=640 * \mathrm{EC}(\mathrm{dS} / \mathrm{m}=$ deci-Siemens per meter $)$, where $\mathrm{EC}_{\mathrm{w}}<5$ $\mathrm{dS} / \mathrm{m}$, or TDS $(\mathrm{mg} / \mathrm{L})=800 * \mathrm{EC}(\mathrm{dS} / \mathrm{m}=$ deci-Siemens per meter), where $\mathrm{EC}_{\mathrm{w}}>5 \mathrm{dS} / \mathrm{m}$ units is used to calculate salinity level of water [16-19].

Another factor of water is directly related to the quality of natural/ irrigation, even salinity of water, this is $\mathrm{PH}$. The acidity or basicity of water is expressed as $\mathrm{pH}(<7.0$ acidic; $>$
7.0 basic) [20]. The normal $\mathrm{pH}$ range for neutral, irrigation, and saline water are 7 , from 6.5 to 8.4 , and 8.4 respectively. Water's acidity and alkalinity mainly depends on the two major factors: $\mathrm{pH}$ and temperature. If the temperature of water increases the $\mathrm{pH}$ level decrease-it means water is acidic, and when temperature decrease the $\mathrm{pH}$ level in water increase-it means water is alkaline [13]. Upon studying and analyzing the factors mentioned above researchers classified water type granularly, as shown in Table I.

\section{ANALYTICAL MODEL FOR THE PROPOSED SYSTEM}

The knowledge-based system (KBS) developed for this work depends on the structure of expert system. The structure of expert system has five main components: user interface, working memory, inference engine, knowledge base, and explanatory facility [14], with these major ES components there are some additional components in our proposed system namely: system interface, sensors, water source, and users, as shown in Figure 2. The major components are briefly explained below.

Knowledge base - declarative representation of the expertise, often in IF THEN rules;

Working storage - the data which is specific to a problem being solved;

Inference engine - the code at the core of the system which derives recommendations from the knowledge base and problem-specific data in working storage;

User interface - the code that controls the dialog between the user and the system.

Explanation Facility-Illustrates to the user how and why the system gave a certain cause for the failure, i.e. explains the reasoning of the system to the user.

In this proposed expert system researchers used forward chaining (reasoning) method where an interpreter uses a set of rules and a set of facts to perform an action [15]. This method involves checking the condition part of a rule to determine whether it is true or false. If the condition is true, then the action part of the rule is also true. This procedure continues until a solution is found or a dead end is reached. Forward chaining is commonly referred to as data-driven reasoning. This method composed of three components. These are: The rule set; a working storage area which contains the current state of the system; an inference engine which knows how to apply the rules.

The rules are of the form: left hand side (LHS) ==> right hand side (RHS), in short: IF---THEN. The LHS is a collection of conditions which must be matched in working storage for the rule to be executed. The RHS contains the actions to be taken if the LHS conditions are met.

The execution cycle of the system is:

Select a rule whose left hand side conditions match the current state as stored in the working storage.

Execute the right hand side of that rule, thus somehow changing the current state.

Repeat until there are no rules which apply. 
Table 1. An extended and granular classification of water types

\begin{tabular}{|c|c|c|c|c|c|}
\hline $\mathbf{P h}$ & $\begin{array}{c}\text { TDS } \\
(\mathrm{mg} / \mathrm{L})\end{array}$ & $\begin{array}{c}\mathrm{EC} \\
(\mu \mathrm{S} / \mathrm{cm})\end{array}$ & $\begin{array}{c}\text { T (Degree } \\
\text { Celsius) }\end{array}$ & Water Type & Application/ Affect \\
\hline $6.5-6.9$ & $0-50$ & $<82$ & $21-32$ & Fresh, Very soft water & $\begin{array}{l}\text { Ideal drinking water from reverse } \\
\text { osmosis with excellent taste. Prefer to } \\
\text { fresh water fish, Aquatic life. }\end{array}$ \\
\hline $6.5-6.9$ & $50-150$ & $82-250$ & $21-32$ & Fresh water, Soft water & $\begin{array}{l}\text { Excellent drinking water from carbon } \\
\text { filtration, mountain springs. Prefer to } \\
\text { fresh water fish, Aquatic life. }\end{array}$ \\
\hline $6.5-6.9$ & $150-300$ & $250-500$ & $21-32$ & Fresh water, & $\begin{array}{l}\text { Excellent tap water with typical human } \\
\text { taste Prefer to fresh water fish, Aquatic } \\
\text { life. }\end{array}$ \\
\hline $6.5-6.9$ & $\begin{array}{l}300- \\
1200\end{array}$ & $500-2000$ & $21-32$ & $\begin{array}{l}\text { Fresh water with a Bitter taste, } \\
\text { Mere acidic water, Surface water }\end{array}$ & $\begin{array}{l}\text { Acceptable for fresh water fish, plants } \\
\text { and cattle }\end{array}$ \\
\hline $7-7.5$ & $0-50$ & $<82$ & $21-32$ & $\begin{array}{l}\text { Neutral water, fresh and soft } \\
\text { water }\end{array}$ & $\begin{array}{l}\text { Excellent and ideal drinking water from } \\
\text { reverse osmosis, Acceptable for fresh } \\
\text { water fish }\end{array}$ \\
\hline $7-7.5$ & $50-150$ & $82-250$ & $21-32$ & $\begin{array}{l}\text { Neutral water, fresh and soft } \\
\text { water }\end{array}$ & $\begin{array}{l}\text { Ideal bottled drinking water from carbon } \\
\text { filtration, Acceptable for fresh water fish }\end{array}$ \\
\hline $7-7.5$ & $150-300$ & $250-500$ & $21-32$ & Fresh water and neutral water & $\begin{array}{l}\text { Excellent tap water with typical human } \\
\text { taste (medium to hard), } \\
\text { Prefer to fresh water fish }\end{array}$ \\
\hline $7-7.5$ & $300-600$ & $500-1000$ & $21-32$ & $\begin{array}{l}\text { Hard to very hard and good fresh } \\
\text { water, }\end{array}$ & $\begin{array}{l}\text { Unpleasant taste, presence no serious } \\
\text { burden to live stock, } \\
\text { Prefer to fresh water fish }\end{array}$ \\
\hline $7-7.5$ & $600-900$ & $1000-1500$ & $21-32$ & Fair fresh water & Presence no serious burden to live stock \\
\hline $7-7.5$ & $\begin{array}{l}900- \\
1200\end{array}$ & $1500-2000$ & $21-32$ & Poor fresh water & Presence no serious burden to live stock \\
\hline$<6.5$ & $0-300$ & $<500$ & $21-32$ & Severe acidic water & Bitter metallic taste and corrosion \\
\hline 7 & $0-50$ & $<82$ & $>32$ & Acid water & $\begin{array}{l}\text { If the Temperature in degree Celsius } \\
\text { increases it means the } \mathrm{pH} \text { level will be } \\
\text { decreased. As a result the Acidity level } \\
\text { will be increased }\end{array}$ \\
\hline 7 & $0-50$ & $<82$ & $<21$ & Alkaline water & $\begin{array}{l}\text { If the Temperature in degree Celsius } \\
\text { decreases it means the } \mathrm{pH} \text { level will be } \\
\text { increased. As a result the Alkaline level } \\
\text { will be increased }\end{array}$ \\
\hline $7.5-8.4$ & $\begin{array}{l}1200- \\
3000\end{array}$ & $2000-5000$ & $21-32$ & $\begin{array}{l}\text { Slightly saline water, Mildly } \\
\text { basic }\end{array}$ & $\begin{array}{l}\text { Unacceptable for live stock, should affect } \\
\text { health or performance but may cause } \\
\text { temporary mild diarrhea }\end{array}$ \\
\hline $7.5-8.4$ & $3000-$ & $5000-8000$ & $21-32$ & Moderately saline water, Mildly & May cause diarrhea \\
\hline
\end{tabular}




\begin{tabular}{|l|l|l|l|l|l|}
\hline & 5000 & & & basic & \\
\hline $7.5-8.4$ & $\begin{array}{l}5000- \\
15000\end{array}$ & $\begin{array}{l}8000- \\
25000\end{array}$ & $21-32$ & $\begin{array}{l}\text { Brackish to Highly Brackish } \\
\text { water, Mildly basic }\end{array}$ & $\begin{array}{l}\text { Safety for adult ruminants, avoided for } \\
\text { Cattles and baby calves }\end{array}$ \\
\hline $7.5-8.4$ & $\begin{array}{l}15000- \\
30000\end{array}$ & $\begin{array}{l}25000- \\
50000\end{array}$ & $21-32$ & $\begin{array}{l}\text { Saline to highly saline water, } \\
\text { Mildly basic }\end{array}$ & $\begin{array}{l}\text { Should be avoided, young animals can be } \\
\text { affected }\end{array}$ \\
\hline $7.5-8.4$ & $\begin{array}{l}30000- \\
40000\end{array}$ & $\begin{array}{l}50000- \\
65000\end{array}$ & $21-32$ & $\begin{array}{l}\text { Sea water, contains high degree } \\
\text { of salts }\end{array}$ & $\begin{array}{l}\text { Acceptable for sea fish, sea animals, and } \\
\text { sea plants }\end{array}$ \\
\hline $7.5-8.4$ & $\begin{array}{l}40000- \\
300000\end{array}$ & $\begin{array}{l}65000- \\
500000\end{array}$ & $21-32$ & $\begin{array}{l}\text { Brine, Mildly basic } \\
\text { Unsafe. Should not be used under any } \\
\text { conditions }\end{array}$ & $\begin{array}{l}\text { Severely alkaline water, Hard } \\
\text { water }\end{array}$ \\
\hline$>8.4$ & $>40000$ & $>65000$ & $21-32$ & Rain water & Soda like taste, should be avoided \\
\hline $5.3-5.8$ & $10-15$ & $17-25$ & $21-32$ & & \\
\hline
\end{tabular}

The syntax of the rules is:

rule $<$ rule id $>$ :

$[<\mathrm{N}\rangle$ : $<$ condition $>, \ldots \ldots .$.

$$
==>
$$

$[<$ action>, ....].

Where: rule id - a unique identifier for the rule; $\mathrm{N}$ - optional identification for the condition; condition - a pattern to match against working storage; action - an action to take. The Figure

3 mentioned below represents the concept of the forward chaining algorithm.

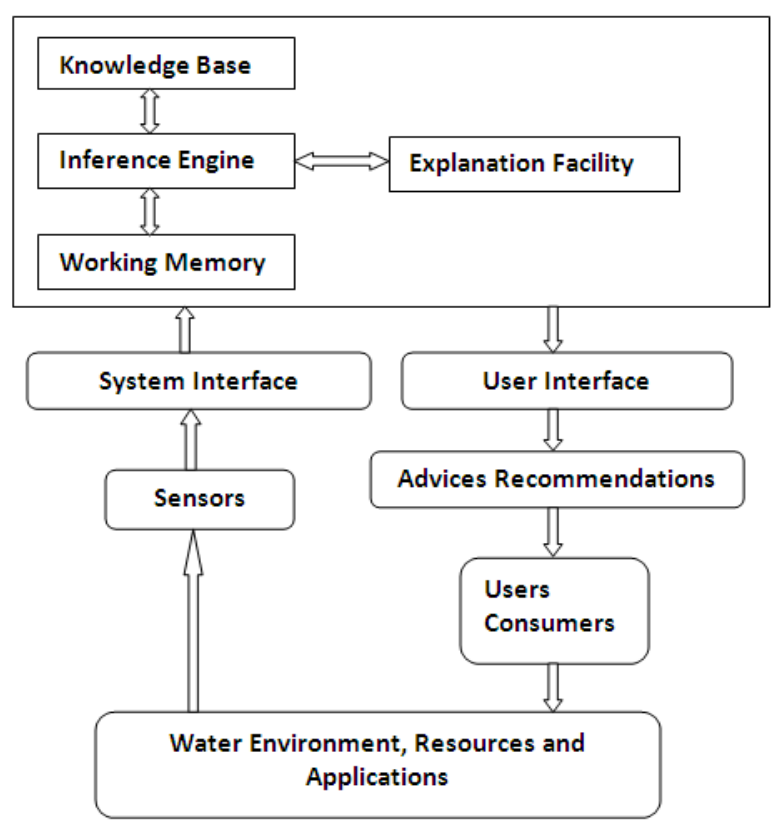

Fig 2: Structure of proposed expert system

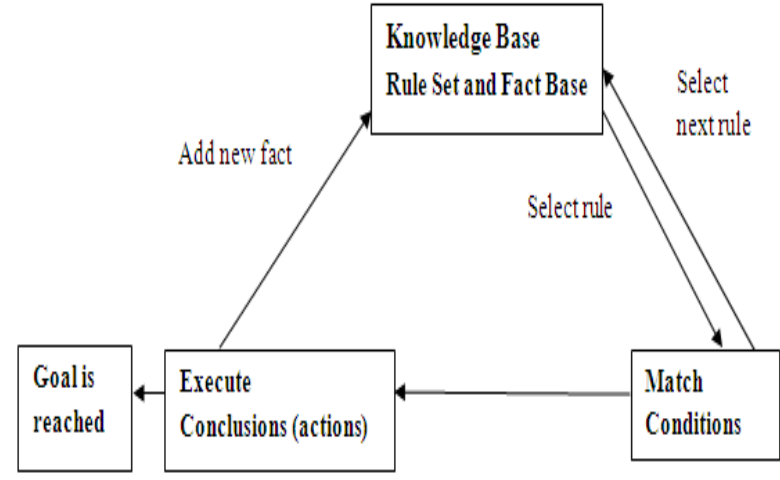

Fig 3: The forward chaining algorithm model for the proposed system.

\section{DESIGN OF THE PROPOSED EXPERT SYSTEM}

The Knowledge Engineer acquires knowledge from experts in specific field, through standardization process, and sorts out the collected knowledge from experts to formed rules. In water types identification system, the way of knowledge representation is production rule. The production rule uses the presentation way of "IF P THEN Q", P is precondition, and Q is conclusion [16].

The proposed expert system's knowledge base is developed by decision table or knowledge base table. Where the condition part of the decision table is called the condition stub

and the action part the action stub shown in Figure 4 as mentioned below. Each column represents a rule, and when all of the conditions in a column are satisfied, the action or actions designated in that column represent the recommended decision [17]. 


\begin{tabular}{|l|l|l|l|}
\hline & Rule1 & Rule2 & Rule3 \\
\hline Condition1 & & & \\
\hline Condition2 & & & \\
\hline Action1 & & & \\
\hline Action2 & & & \\
\hline
\end{tabular}

Fig 4: A decision table.

The connection between decision Tables and rules in a rulebased expert system is easily seen in the following decision table. "Y" and "N" in the condition stub represent "Yes" and

"No" ("T" and "F" could be used representing "True" and

"False") and an "X" in the action stub means the action is recommended. "-" in a cell means the condition or action is irrelevant, shown in Table 2 [17]. Using the concepts getting from the Table 2 a new table 'Table 3' was developed, which shows the combination between decision table rules for our proposed system.

Table 2: Combination between decision table rules in rule based expert system

\begin{tabular}{|l|l|l|}
\hline & Rule1 & Rule2 \\
\hline Condition1 & Y & Y \\
\hline Condition2 & - & - \\
\hline Condition3 & Y & Y \\
\hline Action1 & X & \\
\hline Action2 & & X \\
\hline Action3 & & \\
\hline
\end{tabular}

Table 3: Combination between decision table rules in rule based expert system for proposed system (e.g. RULE1, 13, 40)

\begin{tabular}{|l|l|l|l|}
\hline & Rule1 & Rule13 & Rule40 \\
\hline PH level & 7 & $6.5-6.9$ & 8 \\
\hline TDS level & $0-50$ & $300-1200$ & $30,000-40,000$ \\
\hline EC level & $0-81.8$ & $470-1875$ & \\
\hline $\begin{array}{l}\text { Temperatu } \\
\text { re level }\end{array}$ & $21-32$ & $21-32$ & $21-32$ \\
\hline
\end{tabular}

\begin{tabular}{|c|c|c|c|}
\hline$($ degree $C)$ & & & \\
\hline $\begin{array}{l}\text { The } \\
\text { recommen } \\
\text { dation } \\
\text { (action) }\end{array}$ & $\begin{array}{l}\text { Neutral } \\
\text { water, } \\
\text { excellent } \\
\text { quality, ideal } \\
\text { drinking } \\
\text { water, very } \\
\text { soft. }\end{array}$ & $\begin{array}{l}\text { Fresh } \\
\text { water, but } \\
\text { with a bitter } \\
\text { taste. Mere } \\
\text { acidic. } \\
\text { Acceptable } \\
\text { for fresh } \\
\text { water fish, } \\
\text { plants, and } \\
\text { cattle. }\end{array}$ & $\begin{array}{l}\text { Sea water. } \\
\text { Contains high } \\
\text { degree of salts. } \\
\text { Acceptable for } \\
\text { sea fishes, } \\
\text { animals, and } \\
\text { plants. }\end{array}$ \\
\hline
\end{tabular}

The rule-based shell in proposed ES stores the knowledge in rules, which are logic-based structures, as shown in Figure 5.

The knowledge based system makes inferences by deciding which rules are satisfied by facts stored in the working memory and executes the rule with highest priority and propose proper correcting solution. The rules whose patterns are satisfied by facts in the working memory are stored in the agenda part of the inference engine. Figure 6 explains the inference process of the system using the rules listed in Figure 5 and Figure 7 shows the relationships between the rules used in this system.

For expert systems to work in the real world they must also be able to deal with uncertainty because the expert's rules might be vague or the user might be unsure of answers. In our system, the knowledge base contains data that are based on certain and proven facts and it has the capability to handle a user's uncertainty.

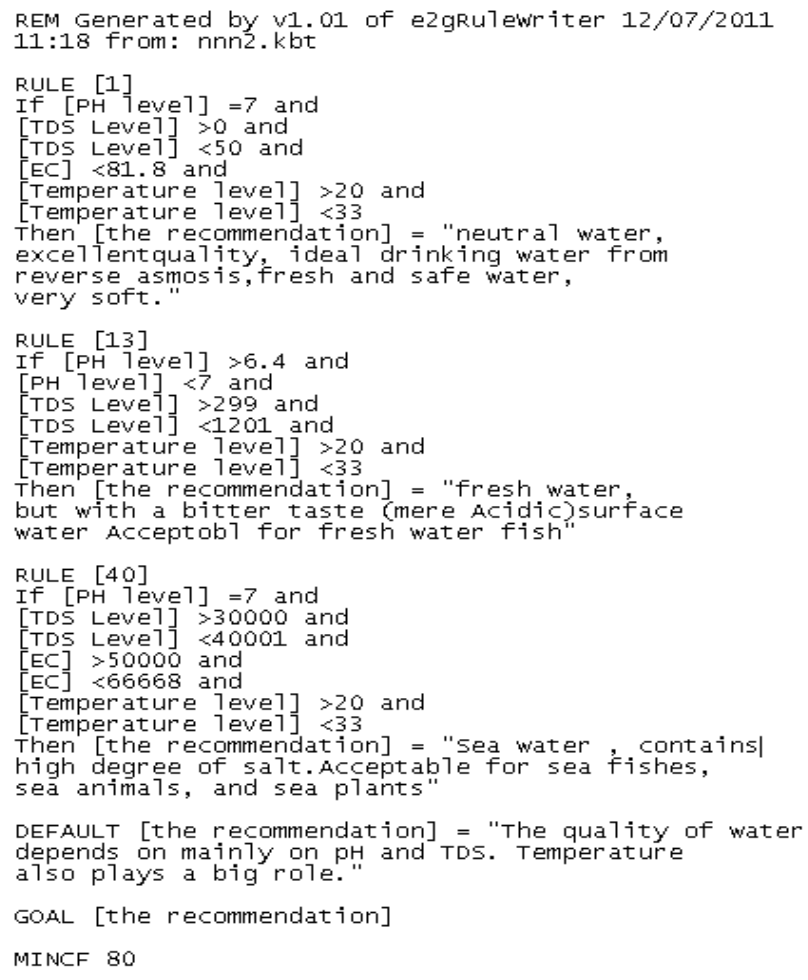

Fig 5: Storage of knowledge in the rules of ES. 


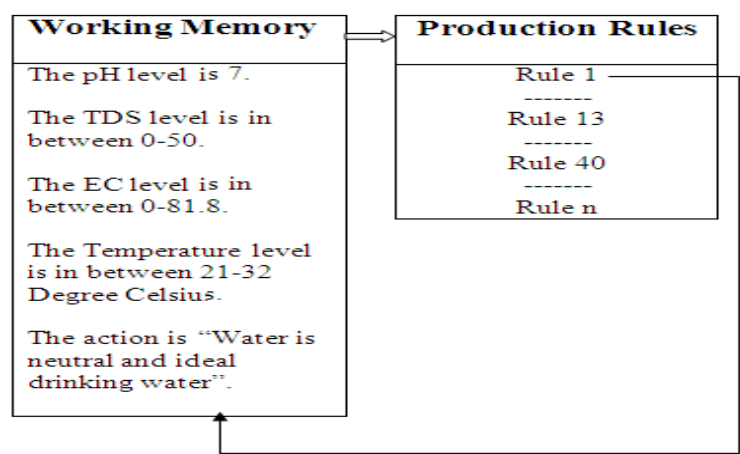

Fig 6: Production system after the Rule 1 is fired

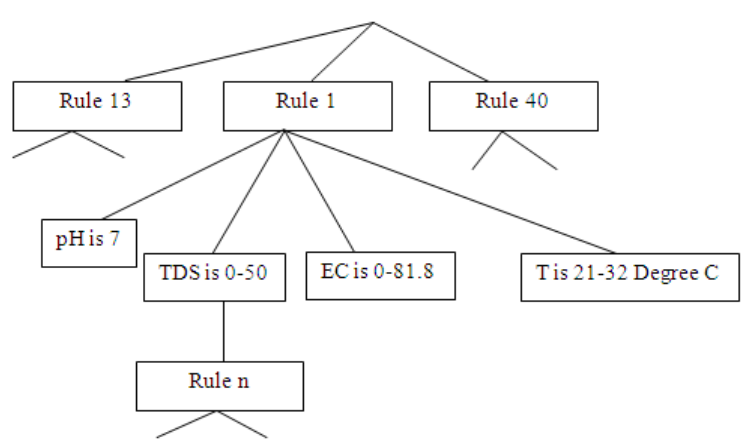

Fig 7: Relationships among Rules

\section{IMPLEMENTATION OF THE PROPOSED EXPERT SYSTEM}

To implement this ES for water types identification webenabled, knowledge-based e2gRuleWriter decision table software and Java applet-based e2gRuleEngine Knowledgebased shell that provides an interactive user interface are used All of these above mentioned software are free for private, educational, and commercial use [17].

The proposed web-enabled expert system utilizes a combination of qualitative and quantitative procedures for water quality types identification. The mixture of both provides reliability to the technical process and facilitates knowledge interaction and analysis. The proposed ES for water types identification has been successfully implemented and validated. The results show that basic decision making procedures are very satisfactory. ES starts by displaying its main window as shown in Figure 8. The user is expected to click the button to choose the option for identifying water quality types. In this section the researchers have randomly selected the values for $\mathrm{pH}$, TDS, EC, and $\mathrm{T}$ to observe the result and recommendation.

An Expert System to Identify the Types of Water Quality

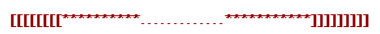

Help Me to Loentify water Quality Type

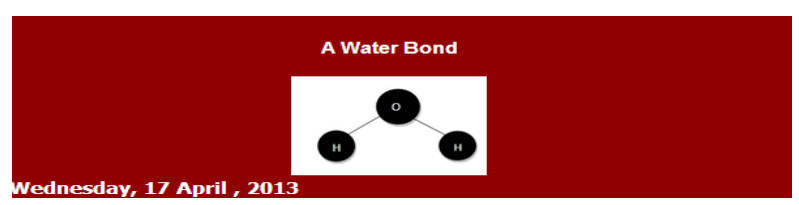

Fig 8: Expert System front page
The system asks the user to give information or date about his/ her water $\mathrm{pH}$, TDS, EC, and temperature-T levels as shown in the following figures $9,10,11$, and 12 .

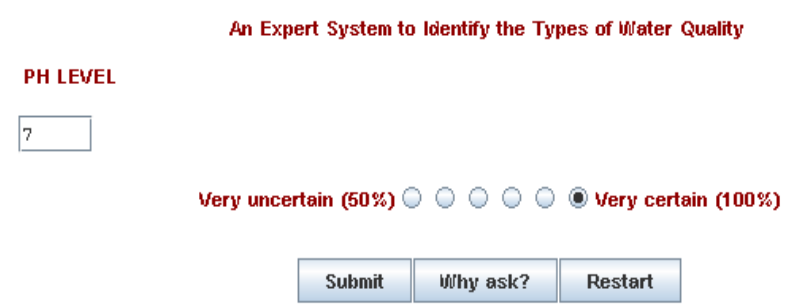

Fig 9: Users must input pH level of their water here.

In this figure it is shown that researchers have selected UF very certain. After input data user must select submit button to go to the next step. Users also may push why ask button to know about the reason of using $\mathrm{pH}$ value. If the value he has given not appropriate he/ she may restart the system again.

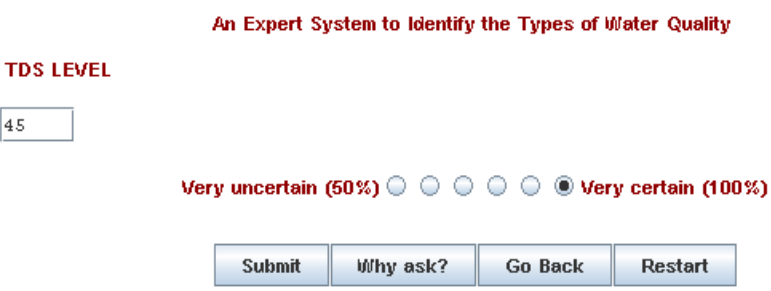

Fig 10: Users must input data of TDS level here

An Expert System to Identify the Types of Ifoter Quality

EC level

80 Very uncertain (50\%) 000000 very certain (100\%)

\begin{tabular}{|l||l||l|l|}
\hline Submit why ask? & Go Back & Restart \\
\hline
\end{tabular}

Fig 11: Users must input data of EC level here

$$
\text { An Expert System to Identify the Types of Woater Quality }
$$

TEMPERATURE LEVEL

25

Very uncertain (50\%) 000000 very certain (100\%)

\begin{tabular}{|c|c|c|}
\hline Submit & Why ask? & Go Back \\
\hline
\end{tabular}

Fig 12: Users must input data of $T$ level here

After giving all the data required for the system users are expected to get the result as shown in figure 13 .

As we have seen this section also have some the options for users to get assistance from the system, such as explain, all conclusion, go back, and restart the system.

After pressing on the option Explain as shown in the previous figure 13, the users will get the total info about his dialogue with our ES as shown in figure 14. 


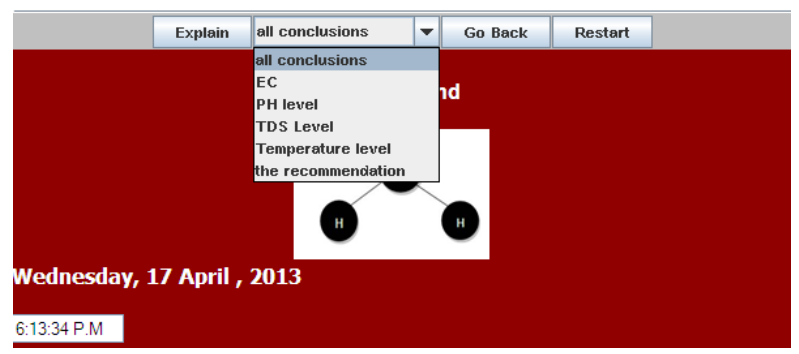

Fig 13: Final recommendation depicted from the ES.

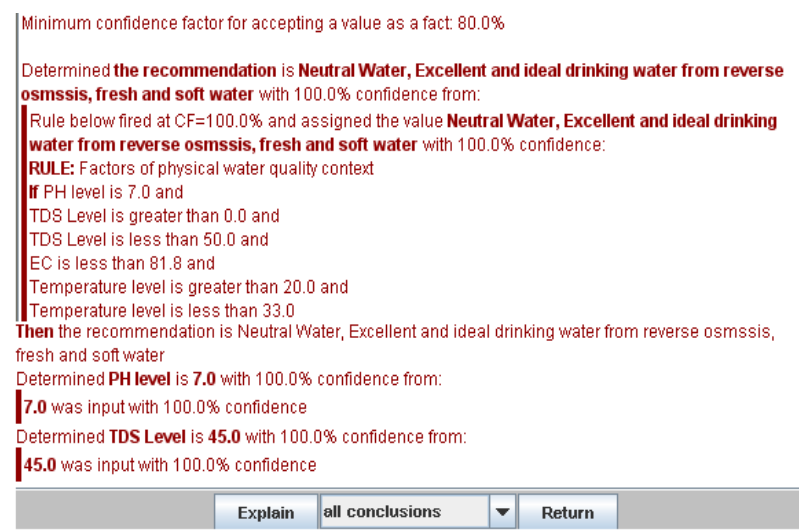

Fig. 14: ES explanation according to users' information

Our ES also provided a short tutorial for the users as shown in figure 15 .

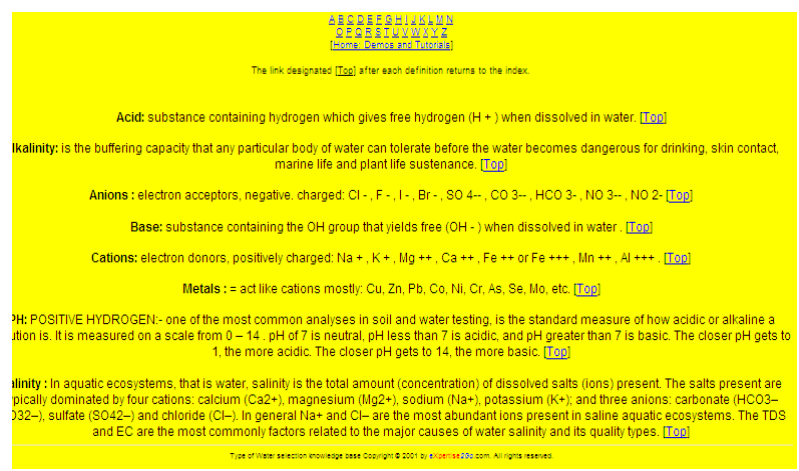

Fig 15: An ES short tutorial for the users

\section{CONCLUSION AND FUTURE WORK}

In this paper an expert system to identify the major water types was developed and implemented. The quality of water is a very vital issue all around the world, especially in ariditybased regions, and of course this quality depends on physical, chemical and microbiological water quality indicators. All these three indicators are varying region to region due to precipitation, natural and man-made contaminant, etc. In this paper researchers gave their attention over the physical and chemical factors. The researchers hope to work further in this field to analysis and design an expert system to identify the types of water quality using all three water quality indicators mentioned above. By using the whole procedures researchers used for the current ES, our future target is to develop a new
ES for the south-east regions of Asia, where arsenic and iron in water are the major issues for health, irrigation, and even for fisheries and plants life. In near future, researchers have some plans to use wireless sensor networks (WSN) for getting real time data/ facts from the remote sources of water and get analysis through expert system. This system never gave the wrong recommendation/ action according to the rules used. In summary, the system has the characteristics of good expert systems, such as high performance, adequate response time, understandability.

\section{REFERENCES}

[1] Joseph Giarratano, Gary Riley (2004). Expert Systems: Principles and Programming, Fourth Edition.

[2] Shu-Hsien Liao (2005). Expert system methodologies and applications a decade review from 1995 to 2004 Expert Systems with Applications, 28, 93-103.

[3] UnitedNations:http://www.un.org/waterforlifedecade/qua lity.shtml

[4] Water's important characteristics: http:/ www. nscdelhi.org/national-science-seminar.php? menu $=11$

[5] A. Karafistan, F. A. Colafokru, Physical, Chemical, and Microbiological Water Quality of the Manyase Lake, Turkey, mitigation and adaption strategies ofr global change (2005) 10: 127-143.

[6] University of waterloo, water chemistry 4 life: http://www.science.uwaterloo.ca/ cchieh/cact/applyche $\mathrm{m} /$ waterchem.html

[7] Water glossary: http://www.lenntech.com/waterglossary.htm

[8] Water types: http://www.pondkoi.com/waterquality.htm

[9] WHO:http://www.who.int/water_sanitation_health/resou rcesquality/wqa/en/

[10] World Bank: http://water.worldbank.org/water/topics/ water-resources-management

[11] Water factors: http://www.dwcwater.com/technologies/ others/ water-quality-tester/index.html

[12] EC in Irrigation water: http://www.ext.colostate.edu/ pubs/crops/00506.html

[13] PH: http://www.h2ou.com/h2wtrqual.htm

[14] Ahmad T. Al-Taani. An Expert System for Car Failure Diagnosis, World Academy of Science, Engineering and Technology 122005

[15] Forward chaining method: http://www.myreaders.info/ 07_Expert_Systems.pdf

[16] Production Rules: http://www.ijcaonline.org/journal/ number23/pxc

[17] KB and KBT: http://www.expertise2go.com/ e2g3g/e2g3gdoc/e2gRuleWriterRef.htm 